\title{
Meninas quilombolas: um olhar sobre gênero e lugar
}

\author{
Niñas quilombolas: una mirada a género y lugar
}

\section{Quilombola girls: a glance at gender and place}

\author{
Juliana Berg \\ bergjuliana@gmail.com \\ Mestranda do PPG em Educação da UNICENTRO \\ Carla Luciane Blum Vestena \\ clbvestena@gmail.com \\ Professora Doutora do PPG em Educação da UNICENTRO
}

Resumo: O presente texto traz a percepção de pesquisadores sobre a vulnerabilidade das meninas quilombolas acerca da possível opressão vivida no ambiente escolar. Uma reflexão que equaciona gênero e raça, sob a ótica da psicologia ambiental e do construtivismo de Jean Piaget.

Palavras Chave: Quilombolas. Meninas. Gênero. Psicologia Ambiental. Piaget.

Resumen: Este texto aporta la percepción de los investigadores sobre la vulnerabilidad de los quilombolas niñas acerca de la posible opresión experimentada en el ámbito escolar. Una reflexión que equipara el género y la raza, desde la perspectiva de la psicología ambiental y el constructivismo de Jean Piaget.

Palabras-Clave: Quilombolas. Girls. Género. Psicología Ambiental. Piaget.

Abstract: This paper presents the perception of researchers as to the vulnerability of quilombola girls to possible oppression experienced in the school environment. It is a reflection addressing gender and race, from the viewpoint of environmental psychology and Jean Piaget's constructivism.

Keywords: Quilombolas. Girls. Gender. Environmental Psychology. Piaget. 


\section{INTRODUÇÃO}

Com o propósito de compreender melhor o sujeito que habita em comunidades tradicionais, no ano de 2012 uma equipe da UNICENTRO iniciou pesquisa que pretende estudar a Moralidade e o Conhecimento Socioambiental das crianças que residem na comunidade quilombola Invernada Paiol de Telha em Guarapuava, interior do estado do Paraná ${ }^{1}$ Este artigo procura, mais especificamente, trazer uma percepção da prática da pesquisa em torno da comunidade quilombola, a partir da qual pudemos registrar o comportamento das meninas que vivem em comunidade, nessa região. Objetivamos, portanto, relacionar fatores diversos como gênero, identidade, cultura, educação e ambiente, numa compreensão das relações existentes no âmbito escolar. Contudo, vale reforçar que essa é uma percepção, enquanto pesquisadores, sobre a vulnerabilidade deste sujeito de analise.

Nessa perspectiva, consideramos assim como Ciaramello (2014), que quando estamos em campo com a pesquisa muitas possibilidades se apresentam e ...

[...] ampliamos nossa percepção, olhamos a tudo e a todos não com um olhar neutro, mas domesticados pelas teorias previamente estudadas; buscando conhecer, compreender, mas cuidando para que esse olhar não esteja pautado numa visão etnocêntrica, permitindo assim julgamentos indevidos. (CIARAMELLO, 2014, p 5).

Compreender a origem desse povo, conhecer sua história, seu meio-casa e seu meio-escola, considerar sua cultura e refletir como todos esses aspectos podem influenciar comportamentos, também são objetivos que procuramos atender neste artigo. Para tanto, utilizamos de pesquisa bibliográfica e de análise de vídeos coletados durante a aplicação de dilemas em sala de aula, que seguem pressupostos do método clínico utilizado por Jean Piaget, e na qual pudemos sentir e perceber a submissão das meninas advindas da comunidade quilombola.

Durante a prática da pesquisa, que analisava a moralidade e conhecimento socioambiental, as reflexões das crianças foram orientadas a partir de um protocolo utilizado pelo pesquisador, baseado num roteiro. Foi utilizada entrevista coletiva baseada em dilemas, onde vários elementos são colocados para as crianças, de forma que elas possam refletir sobre todos eles e assim garantir o que La Taille (2006) chamou de "juízo refletido e ponderado".

Por sua flexibilidade, o método clínico permite também, que sejam criadas novas possibilidades, como a utilização de materiais de apoio (fotografias, desenhos, imagens, vídeos, áudios, etc.). Nesta pesquisa optamos por vídeos, por serem um meio de linguagem conhecido pela maioria do coletivo em sala de aula, por trazerem situações específicas relacionadas ao tema proposto e por serem um meio de sensibilização conhecido por todos na sala de aula.

\footnotetext{
${ }^{1}$ Pesquisa aprovada pelo Comitê de Ética, CAAE 01879112.7.0000.0106 e financiada pelo CNPq na chamada MCTI/CNPq/ SPM/MDA n 32/2012.
} 
Após a exibição dos vídeos foram aplicadas situações dilema onde as crianças foram motivadas a decidir sobre o desfecho da história, ao mesmo tempo em que questionamentos e colocações eram efetuados de forma programada. As discussões aconteceram em tempo determinado, equivalente a uma aula de 50 minutos, durante o período escolar e foram gravadas em vídeo.

Durante a aplicação dos dilemas percebemos o comportamento comedido das crianças quilombolas, mais fortemente o das meninas, que pareciam estar sob forte censura, tanto das meninas e meninos da colônia, como também dos meninos da própria comunidade quilombola. Eram olhares, sorrisos e até mesmo palavras que ditavam o silêncio das meninas.

Realizamos um exercício de olhar e de não interferir para refletir, pautando-nos na história do quilombo e mais especificamente na história de Invernada Paiol de Telha, de estudos do gênero e da psicologia ambiental, sempre baseados na teoria de Piaget.

\section{QUILOMBO}

A discussão sobre a construção dos sujeitos, sua identidade e sua relação com os demais é necessária, faz parte de nosso entendimento sobre o múltiplo e expande nosso olhar, nossa percepção para o outro. Provoca o aprofundamento de temas que antes não nos ocorreram, ou que se isso se fez, ocasionalmente, não nos saltou à percepção.

Quando tratamos especificamente dos povos quilombolas podemos falar sobre várias temáticas, pois se sabe que a multiplicidade étnica e cultural brasileira é uma característica conhecida das análises das ciências e estudos educacionais. Entretanto, a percepção clara desta multiplicidade para a população em geral, por meio de ações, não tem expressão significativa, pois esses grupos são considerados muitas vezes como residentes apenas no imaginário nacional. Nesse sentido, destaca-se a emergência das comunidades remanescentes de quilombos, que não desapareceram junto com o sistema escravocrata. Pelo contrário, em 1988 tiveram seu reconhecimento legal e social por meio do Artigo 68 do Ato das Disposições Constitucionais Transitórias.

Quilombo hoje tem significado diferente de décadas anteriores, 70 e 80 , quando a disciplina de História do Brasil nos dava conta apenas do quilombo dos Palmares, numa localidade que era estrategicamente impossível de se chegar. Também está distante de uma definição semântica pura e simplesmente da palavra, embora essa compreensão seja útil para nosso entendimento. Para Munanga:

O quilombo é seguramente uma palavra originária dos povos de língua bantu (Kilombo, aportuguesado: quilombo). Sua presença e seu significado no Brasil tem haver com alguns ramos desses povos bantus cujos membros foram trazidos e escravizados nesta terra. Trata-se de grupos lunda, ovimbundu, nbundo, kongo, inbangala, etc. cujos territórios se dividem entre Angola e Zaire. (MUNANGA, 1996, p. 59). 


\section{E para Leite,}

A palavra "quilombo", que em sua etimologia bantu quer dizer acampamento guerreiro na floresta, foi popularizada no Brasil pela administração colonial, em suas leis, relatórios, atos e decretos, para se referir às unidades de apoio mútuo criadas pelos rebeldes ao sistema escravista e às suas reações, organizações e lutas pelo fim da escravidão no País. Essa palavra teve também um significado especial para os libertos, em sua trajetória, conquista e liberdade, alcançando amplas dimensões e conteúdos. (LEITE, 2008, p. 965).

Mesmo que sua origem seja africana e que quilombo no Brasil seja o termo em uso para comunidades tradicionais originárias da África, há agrupamentos similares em outros países, tanto em história quanto em dificuldades e lutas territoriais. Na América, em países como Cuba e na Colômbia, esses grupos são conhecidos como cimarrónes, na Venezuela recebem o nome de palenques, na Jamaica de cumbes e nas Guianas e nos Estados Unidos os denominados marrons.

Para Ratts (2013, p.131), conhecer grupos com características semelhantes e de outras nacionalidades nos faz perceber que o "aquilombamento" foi um movimento de países colonizados, e que esse fato nos chama atenção para uma possível "pluralidade de situações." Da mesma forma, percebemos realidades plurais em território brasileiro, onde cada agrupamento quilombola assume características diferenciadas dependendo da região em que se encontra. Há comunidades quilombolas em quase todos os estados brasileiros, que assumiram formas e organizações próprias diferentes das do período colonial.

Atualmente algumas dessas organizações participam do cotidiano das cidades estando separadas por marcações de terra bem definidas, próximas ou até mesmo dentro das cidades - quilombos urbanos - e com limites conhecidos. Muitas outras ainda lutam pelo pleito de reconhecimento da posse da terra e de sua identidade e quase todas passam por dificuldades das mais variadas ordens.

Até outubro de 2013, segundo o Ministério da Cultura, a Fundação Cultural Palmares certificou 2.408 comunidades quilombolas no Brasil. A maior concentração de comunidades foi nos estados do Maranhão, Bahia, Pará, Minas Gerais e Pernambuco. A Fundação Cultural dos Palmares menciona perto de aproximadamente 3.000 comunidades entre oficializadas, em processo de oficialização e as não reconhecidas.

A definição, ou até mesmo a compreensão do que se pode afirmar ser quilombo nos dias atuais é assunto polêmico. Isso acontece por todo o valor econômico envolvido nas questões relativas à posse de terra, como também pelo simbolismo enraizado na história, que além de identificá-las pura e simplesmente, também assume conotação caracterizadora, classificadora, legalizadora e algumas vezes até mesmo discriminatória. Portanto, definir quilombo não é tarefa fácil e para Arruti, a respeito das relações raciais, quando falamos dos quilombolas, dos membros dessas comunidades:

Não é possível falar deles sem adjetivá-los. Seja por meio da fórmula legal que lança mão de "remanescentes", ou das tentativas de ajuste desta, por meio de 
“contemporâneos". Seja ainda porque são necessárias distinções entre estes, quando se usa "urbanos" ou "rurais". Ou, quando se quer tipificá-los, por meio de "agrícola", "extrativista", "nômade" etc. Ou, finalmente, quando se fala em "históricos", de forma complementar ou concorrente àquelas formas anteriores, já que falar em "quilombos históricos" tem servido tanto para especificar quanto para deslegitimar os "quilombos contemporâneos". (ARRUTI, 2008, p.1).

Arruti (2008) fala da diversidade de características assumidas pelos quilombos dependendo do período e da área de conhecimento, ou até mesmo do período histórico que analisa esse significado. Para ele, essas diferenças são resultado de ressemantizações desde o período colonial até os dias atuais, perpassando considerações baseadas em fatos históricos, questões políticas, discussões sociais, legais, constitucionalizadoras e culturais.

No Brasil, essas ressemantizações acompanharam também, ao longo do processo de configuração da identidade quilombola, uma cronologia de luta e de fatos significativos na vida dessas comunidades.

As discussões sobre o reconhecimento dos quilombolas tornaram-se mais acaloradas na década de 1970. Nesse período, surgiu o Movimento Negro Unificado Contra a Discriminação Racial (mais tarde abreviado para MNU) que em seu primeiro congresso nacional na Bahia instituiu o dia 20 de novembro como Dia da Consciência Negra. O MNU também reivindicava melhorias na legislação brasileira que historicamente impossibilitavam os negros de deter a posse das terras suas.

A partir da década de 80, a situação da titularidade das terras e o reconhecimento das comunidades começaram a mudar. E em 1988, a Assembleia Nacional Constituinte, após décadas de ditadura, muda a questão quilombola. Coincidência ou não, a nova Constituição Federal nasceu exatamente cem anos depois do fim da escravidão, o que facilitou a inclusão na nova Constituição de alguns artigos que dissessem respeito às políticas afirmativas, como por exemplo o artigo 68 (ADCT) que reconheceu aos "remanescentes de quilombo a propriedade definitiva das terras que estejam ocupando", assim como obrigou o Estado a "emitir-lhes os títulos respectivos". (BRASIL, 1988)

Em 20 de novembro de 2003 foi assinado o decreto presidencial regulamentando o artigo 68, onde em seu Art. $2^{\circ}$ definia-se quem seriam os grupos tradicionais ditos quilombos ou remanescentes, que requeriam terras de seus ancestrais. Nesse artigo consta:

Consideram-se remanescentes das comunidades dos quilombos, para os fins deste Decreto, os grupos étnico-raciais, segundo critérios de autoatribuição, com trajetória histórica própria, dotados de relações territoriais específicas, com presunção de ancestralidade negra relacionada com a resistência à opressão histórica sofrida. § $1^{\circ}$ Para os fins deste Decreto, a caracterização dos remanescentes das comunidades dos quilombos será atestada mediante autodefinição. (BRASIL, 2003).

Para Associação Brasileira de Antropologia - ABA, que reconhece o processo de ressemantização sofrido pelo termo e tem nas últimas décadas se preocupado muito em estudar essas comunidades, o quilombo tem hoje significado ampliado sendo que: 
O termo quilombo tem assumido novos significados na literatura especializada e também para grupos, indivíduos e organizações. Vem sendo ressemantizado para designar a situação presente dos segmentos negros em regiões e contextos do Brasil. Contemporaneamente, quilombo não se refere a resíduos ou resquícios arqueológicos de ocupação temporal ou de comprovação biológica. Não se trata de grupos isolados ou de população estritamente homogênea, nem sempre foram constituídos a partir de movimentos insurrecionais ou rebelados. Sobretudo consistem em grupos que desenvolveram práticas cotidianas de resistência na manutenção e na reprodução de seus modos de vida característicos e na consolidação de território próprio. A identidade desses grupos não se define por tamanho e número de membros, mas pela experiência vivida e as versões compartilhadas de sua trajetória comum e da continuidade como grupo. Neste sentido, constituem grupos étnicos conceitualmente definidos pela antropologia como um tipo organizacional que confere pertencimento, por meio, de normas e meios empregados para indicar afiliação ou exclusão. (O'DWYER, 2002, p. 18).

\section{RELACIONANDO PARANÁ, GUARAPUAVA, DISTRITO DE ENTRE RIOS E INVERNADA PAIOL DE TELHA}

A diáspora africana para o Paraná, na região sul do país, é relatada em muitos textos. Segundo Cruz e Salles (2008), os primeiros negros vieram com a implantação do sistema colonial, ligados inicialmente à procura de ouro no litoral. Alguns serviram ao setor de mineração, principalmente na região do Vale do Ribeira, sendo segundo Cruz e Salles (2008), africanos vindos de Guiné, Angola e Moçambique. Posteriormente os africanos integraram atividades em latifúndios pastoris e agrícolas.

No estado do Paraná, segundo a Fundação Cultural dos Palmares, existem aproximadamente 86 comunidades quilombolas, 37 já certificadas. Na região centro-sul, próximo ao município de Guarapuava estima-se que existam aproximadamente cinco comunidades, sendo apenas a Comunidade Invernada Paiol de Telha reconhecida.

Paiol de Telha está atualmente dividida. Essa é uma comunidade quilombola em situação bastante complexa e especial por sua luta pela garantia da terra e pela marcação dual das culturas existentes num mesmo espaço. Expulsos de suas terras, parte dos quilombolas vivem em localidades próximas, reagrupadas em quatro núcleos: Barranco (localizado às margens da área original, no município de Reserva do Iguaçu), nos municípios de Pinhão e Guarapuava, e em um Assentamento da Reforma Agrária, no Distrito de Entre Rios, na chamada Colônia Vitória onde os habitantes em grande maioria são de descendência alemã suábica, da região do Danúbio. Nesse Assentamento encontram-se as lideranças de Paiol de Telha e também aproximadamente 68 famílias remanescentes onde residem aproximadamente 50 crianças em idade escolar, os sujeitos desta observação.

Os registros a respeito da comunidade de Paiol de Telha são poucos. Existem estudos das áreas do Turismo, História, Geografia e Antropologia, sendo destaque para essa 
última a obra da antropóloga Mirian Furtado Hartung, de 2004, que se constituiu uma "importante síntese histórica" como mencionado por Ilka Boaventura Leite em prefácio da obra O Sangue e o Espírito dos Antepassados. (LEITE, 2011).

Originalmente a comunidade da Invernada Paiol de Telha habitava terras próprias, em outra localidade na Fazenda Capão Grande, em área também conhecida como Fundão (Distrito de Pedro Lustosa, município Reserva do Iguaçu, PR). Deixada à aproximadamente 17 escravos libertos e outros 10 ainda escravizados, as terras foram repassadas em testamento pela fazendeira Dona Balbina Francisca de Siqueira, em 1860. Segundo Hartung (2004), anos depois de receberem a terra, em 1875, os negros do Fundão foram usurpados desse território por Pedro Lustoza de Siqueira. Começava então uma história de desencontros que ainda envolvem os quilombolas e a Cooperativa Agrária Agroindustrial Entre Rios, instalada em Colônia Vitória.

Em 19 de dezembro de 2013 foi julgado pelo Tribunal Regional Federal (TRF) da quarta região, em Porto Alegre, a ação em que a Cooperativa Agrária questionou o processo administrativo do INCRA para a titulação de terras da Comunidade Quilombola do Paiol de Telha. O resultado desse processo, muito além de uma ação isolada, poderia abrir um precedente judicial para que outras ações vitimassem comunidades quilombolas com processos similares em todo Brasil. A associação dos quilombolas de Paiol de Telha, a frente com D. Ana Maria, uma das líderes no Assentamento, mobilizou os quilombos de todo país para a questão, assim como buscou apoio nos mais variados âmbitos. O resultado foi o ganho de causa à comunidade que em acórdão dos documentos do julgamento menciona: “Arguição de inconstitucionalidade que se rejeita." (TRF, 2013, p.1)

Paiol de Telha ainda têm muito por lutar: a contínua busca pela afirmação de seu reconhecimento; o regresso das famílias que ainda não foram assentadas e vivem em situação de risco; como também a educação das crianças quilombolas são questões que preocupam a comunidade. Para nossas observações consideraremos as questões relativas à educação.

Um aspecto importante em Paiol de Telha é a ausência de uma escola no espaço quilombola. Está ainda em trâmite um projeto junto ao Ministério da Educação que confere à comunidade o direito à escola e essa situação obriga as crianças a se deslocarem para estudar e a participarem cada vez mais da cultura da Colônia Vitória, incorporando meios de educação e de interação cultural que não os seus.

Essa inversão de culturas provoca o enxergar seu lugar de forma diferente dos demais, que não é apenas uma questão de ponto de vista, mas sim de uma construção, de uma construção que depende de muitos fatores. Para Yi-Fu Tuan, a ideia e o sentimento relacionados à noção de espaço e de lugar - do amplo ao próximo - "são complexos" ... "Originam-se das experiências singulares e comuns. No entanto, cada pessoa começa como uma criança." E como uma criança percebe seu lugar? Segundo Tuan, há uma relação biológica e cultural na relação com seu lugar, uma visão construída durante o desenvolvimento físico, intelectual e psicológico dela que se amplia a medida que a criança atinge o comum, o permanente. "O espaço transforma-se em lugar à medida que adquire 
definição e significado." (TUAN, 1983, p.151). Para a criança quilombola, mesmo que ela ainda não perceba assim, seu espaço é sua matriz africana e seu lugar é a comunidade quilombola.

Ela irá construir sua percepção de mundo e sua cultura fará sentido e terá significado tão logo ela se veja parte autônoma integrante deste "povo". Sua cultura imprimirá uma razão de pertencimento, de ser e estar numa cultura, de sua identidade. Por isso, a importância para essas comunidades em ter uma escola não está em manter as crianças afastadas de outras, mas principalmente em perceber seu lugar, como um lugar que considera as crianças, que valoriza o fato de sua história e cultura serem repassados, que possa enxergar os princípios da educação quilombola como parte de um espaço múltiplo, coabitado por culturas diversas, onde as crianças se identifiquem e possam ter uma infância construída sem rótulos.

No Brasil, o contexto escolar dessas comunidades é motivo de muitas discussões e ajustes, visto que muitas das crianças e adolescentes remanescentes não possuem escolas na comunidade onde vivem tendo que estudar nas proximidades. Segundo o Censo Escolar de 2012, existem 212.987 estudantes quilombolas matriculados em 2.238 escolas localizadas em áreas de remanescentes de quilombos, sendo que mais de $65 \%$ desses estudantes estão em comunidades localizadas na região Nordeste do país.

\section{RELACIONANDO GÊNERO: MENINA QUILOMBOLA}

Pesquisando sobre gênero, percebe-se que mesmo o tema sendo relativamente novo, aprofundado a partir da década de 80 com a explosão dos Movimentos Feministas na América Latina e no Brasil, existem publicações significativas em diversidade de abordagens teóricas. Revistas como Cadernos Pagu, Revista Latinoamericana de Geografia e Gênero e a Revista Estudos Feministas publicam o pensamento de estudiosos conhecidos no ambiente acadêmico de vários países.

Joan Scott (1989) menciona que dentre as muitas concepções possíveis para a utilização de gênero, as primeiras utilizadas pareciam estar ligadas as feministas americanas que procuravam uma forma de distinção entre o sexo feminino e masculino.

O gênero sublinhava também o aspecto relacional das definições normativas das feminilidades. As que estavam mais preocupadas com o fato de que a produção dos estudos femininos centrava-se sobre as mulheres de forma muito estreita e isolada, utilizaram o termo "gênero" para introduzir uma noção relacional no nosso vocabulário analítico. (SCOTT, 1995, p. 72).

Já no uso do termo mais recentemente, a autora alerta para o fato de que "uma teoria que se baseia na variável única da diferença física é problemática para os(as) historiadores(as): ela pressupõe um sentido coerente ou inerente ao corpo humano - fora qualquer construção sociocultural - e portanto, a não historicidade do gênero em si." (SCOTT, 1995, p.76). A autora menciona em sua definição que para o entendimento de 
gênero é preciso considerar que "o gênero é um elemento constitutivo de relações sociais baseado nas diferenças percebidas entre os sexos e o gênero é uma forma primeira de significar as relações de poder". (SCOTT, 1995, p. 86). A autora acredita que devem ser considerados nessa definição: os símbolos culturais; os conceitos normativos que colocam em evidência interpretações do sentido dos símbolos; a explosão da noção de "fixidade", a descoberta da natureza do debate ou da repressão que leva a aparência de uma permanência eterna na representação binária dos gêneros; e a identidade subjetiva. Nessa direção, Scott (1995) alerta para a necessidade de analisar as relações de poder relacionando a cultura como base de consideração inicial.

O conceito de gênero pode estabelecer várias formas de compreensão, da mais ocasional, movida por assuntos corriqueiros e até mesmo carregados de preconceito, como também a científica em que pesquisas são realizadas com o propósito de compreender como se dão as relações num determinado período de tempo ou universo social, cultural, político, educacional ou econômico. Assim, como menciona Scott, "o gênero é, portanto, um meio de decodificar o sentido e de compreender as relações complexas entre diversas formas de interação humana." (SCOTT, 1995, p.85) Vista assim, a análise equacionando gênero, como parte desse estudo, pode nos levar à compreensão por exemplo, das relações de desigualdade históricas que envolvem os negros quilombolas.

Analisando dados quantitativos, apresentados no I Plano Nacional de Desenvolvimento Sustentável dos Povos e Comunidades Tradicionais de Matriz Africana, desenvolvido para o triênio 2013 - 2015 pelo Governo Federal verifica-se que:

Os dados da Pesquisa Nacional por Amostra de Domicílios - PNAD, do Instituto Brasileiro de Geografia e Estatística - IBGE indicam que o rendimento médio de uma mulher negra é o menor do Brasil, com ganho de $\mathrm{R} \$ 655,70$, ao passo que o rendimento de um homem branco é, em média $R$ \$1.675,10. Os dados referentes à situação de pobreza indicam que $7,4 \%$ das mulheres negras estão na situação de extrema pobreza e 13,4\% em situação de pobreza, enquanto essa proporção para homens brancos é de 2,9\% e 5,6\% respectivamente. (BRASIL, 2013, p. 18).

Esses dados dão conta de estudos sobre a mulher negra em maior quantidade do que sobre o homem negro, numa perspectiva de gênero. A mulher negra, nesse caso aparece como vítima em potencial da opressão de seus pares e também masculina, tanto do negro quanto do branco. Para esse sujeito de pesquisa os números são alarmantes e não se restringem somente a renda, os dados demonstram que as mulheres negras se veem duplamente discriminadas por serem do sexo feminino e afrodescendente.

A discriminação sobre as mulheres negras perpassa planos não conhecidos pelos homens do mesmo grupo racial, tais como os reportados aos direitos reprodutivos, violência doméstica, violência sexual, dupla jornada de trabalho e demais sequelas geradas por uma sociedade machista, como a brasileira. Esse contingente também comumente se vê impactado pelo seu rebaixamento à condição de objeto de prazer sexual dos homens (especialmente simbolizado na figura da mulata) e pela constante violação de sua autoestima nos planos profissional e estético e à marginalização no mercado matrimonial. (BRASIL, 2006, p. 26). 
O Instituto de Pesquisa Econômica Aplicada - IPEA - e o então Fundo de Desenvolvimento das Nações Unidas para a Mulher - UNIFEM, hoje ONU-Mulheres, começaram em 2004 a investir na produção e disponibilização de um amplo conjunto de informações sobre as desigualdades de gênero e raça existentes na sociedade brasileira. $\mathrm{O}$ resultado publicado recentemente em 2013 é o Dossiê Mulheres Negras: Retrato das Condições de Vida das Mulheres Negras no Brasil, que traz informações atualizadas e importantes para analise a partir de cinco grandes referenciais: a situação educacional, a inserção no mercado de trabalho, o acesso a bens duráveis e às tecnologias digitais, a condição de pobreza e a vivência de situações de violência.

Do ponto de vista da situação educacional dessas mulheres negras, constatou-se que as negras ingressam em instituições superiores em quantidade menor que as brancas, mas que ambas procuram modalidades de ensino de pouco prestígio, quando comparadas aos homens. Do ponto de vista da inserção no mercado de trabalho, destacam-se os cenários das desigualdades de gênero e raça no que tange aos rendimentos. Neste âmbito, observa-se nitidamente um contraste frente aos dados sobre educação. Mesmo sendo mais escolarizadas que os homens, as mulheres brancas e negras têm salários inferiores aos dos homens de seu grupo de cor.

Quanto ao acesso a bens duráveis e às tecnologias digitais, o dossiê permite perceber alguns dos efeitos materiais do processo de subordinação das populações femininas, negras, rurais e nordestinas que se encontram em situação bastante inferior às demais populações. Para a condição de pobreza afirma-se a feminilização e a negritude da pobreza no país. E por fim, sobre a vivência de situações de violência, de uma maneira geral, fica nítida na leitura dos dados que a agressão física obedece padrões diferenciados e maiores para as mulheres segundo raça/cor.

Diante dos dados apresentados, de conteúdo social e econômico de produção da diferença em sujeitos de cultura diversa da considerada heteronormatizada e de raiz europeia, podemos imaginar a incidência de discursos constrangedores tanto externalizados e verbalizados, quanto internalizados, percebidos e sentidos pelas mulheres negras que se reconhecem em situação identitária inferior.

As mulheres negras são vitimadas desde meninas. A reprodução dos fatores descritos acima pode até mesmo em alguns casos atingir dimensões reduzidas, mas qual seria o impacto na infância? A menina quilombola também é, assim como a mulher negra, vitimada em seu contexto vivencial?

As relações que envolvem a infância da menina quilombola são duais, fortes e muitas vezes seguem em caminhos opostos de compreensão. Assim também são as relações envolvendo a mulher quilombola. Isso porque, cada comunidade quilombola mantém modos de fazer e agir diferenciados de outras comunidades, onde a mulher quilombola, assim como a menina, assumem papéis e identidades diversos.

Em Invernada Paiol de Telha a relação de respeito e de poder ocorre pelo valor da ancestralidade e o mais velho, seja ele homem ou mulher, é quem detém maior informação e por isso é detentor do respeito dos quilombolas. Porém, cabe à mulher a formação das crianças e a instrução relativa aos costumes daquela comunidade: 
Nesse processo de passagem de conhecimentos, a mulher negra é a educadora por excelência. Ela sempre guardou os saberes e os cultivou e transmitiu em todos os lugares por onde passou. Ela é identificada com a ancestralidade, porque incorpora essa ancestralidade, nos papéis de mãe, mulher (esposa, companheira) professora, enfermeira, mãe de santo, filha de santo, ekede ou makota, mestre, contramestre ou praticante de capoeira, benzedeira, curadora, conhecedora dos segredos da natureza. Ela realiza essas lutas e ações cotidianas com dignidade e pela DIGNIDADE da família negra. (SIQUEIRA, 2005, p. 37).

Em outras comunidades quilombolas, além do papel de educadoras, são também as mulheres que negociam aspectos relacionados à terra junto aos fazendeiros e INCRA, como é o caso da Comunidade Quilombola de Mata Cavalo, no estado de Mato Grosso. Manfrinate relata que:

Quando as mulheres quilombolas contavam as histórias dos despejos, colocavam as atuações femininas em alta consideração. A resistência e a luta no quilombo são particularidades assumidas pelas mulheres, são elas que brigam e discutem com os fazendeiros. Na narrativa feita isso era colocado como uma tática de "combate", pois quando havia brigas e os homens quilombolas entravam na frente de batalha, os fazendeiros não tinham nenhum escrúpulo em partir para a agressão física, e, como contavam com armas de fogo e empregados contratados justamente para esse fim, os quilombolas acabavam sofrendo muito. Porém, com as mulheres quilombolas tomando a frente da luta os fazendeiros relutavam um pouco em agredi-las e a discussão ficava só nas ofensas verbais. Para elas isso garantia um papel importante no quilombo. (MANFRINATE, 2011, p. 20).

Uma das hipóteses para adoção dessa estratégia de negociação estaria na cultura de suas antepassadas, pois segundo a autora constatou "o poder feminino no quilombo é o que chamam de herança das antigas guerreiras africanas, que implica numa grande força às suas descendentes e a qual elas sabem fazer bom uso". (MANFRINATE, 2011. p. 20).

Visto dessa forma, o gênero é, como afirmado, um meio de decodificar a educação e de compreender as relações sociais complexas de aprendizado entre os quilombolas na atualidade, como também em sua história, uma vez que a mulher negra e quilombola vive toda forma de discriminação e subjetivação e se vê parte de um contexto que se modifica no curso de suas relações sociais.

Em visita às escolas da Colônia Vitória frequentadas pelas crianças quilombolas de Paiol da Telha, foi observar que as crianças interagiam emitindo sua opinião sobre temas relacionados ao objetivo da pesquisa, mas o comportamento das crianças quilombolas era comedido, quase nulo, reflexivas mas sem participação. Como se sentem essas crianças? O que pensam quando percebem nos outros, que mesmo sendo iguais, alguns atributos físicos fazem com que elas se sintam omissas?

Quando estreitamos a discussão inserindo gênero, como parte do recorte que fizemos, estamos dirigindo nosso olhar para as meninas quilombolas, que além de sofrerem 
o impacto de outras culturas que não a sua, são estigmatizadas mesmo de forma inconsciente. E no ambiente escolar essa opressão assume características diversas, podendo estar relacionadas a questões como a opressão masculina, a opressão feminina branca, a opressão pelo professor, a opressão pelo conteúdo repassado que desconsidera questões de diversidade em seu currículo, como também a opressão escolar que segue seu curso desconsiderando a problemática que envolve essas meninas.

Tão complexa quanto as relações vistas na análise de gênero são as relações raciais, elas também podem servir como forma de decodificação na interação do homem com o meio, assim como podem trazer a compreensão de como esse binômio raça-gênero se estabeleceu nas mais variadas culturas.

Os relatos são importantes para nossa compreensão dessas realidades e, por isso consideramos esses, como base de analise nesse estudo, porém carece de aprofundamento a compreensão de como a raça e gênero tem participado das novas realidades culturais e sociais no âmbito escolar. Mesmo que, para alguns esse seja um tema "incômodo" por toda tensão relacionada e por conta do preconceito histórico que engendra ambos os temas, essa compreensão pode se revelar rica em subsídios que possibilitem o entendimento de muitos outros aspectos, como por exemplo a análise que iniciamos buscando a compreensão do ambiente e do lugar quilombola.

\section{RELACIONANDO PSICOLOGIA E PERCEPÇÃO AMBIENTAL}

A compreensão sobre a psicologia ambiental surgiu no Brasil a partir da década de 60, acompanhando estudos publicados na Inglaterra, Canadá, Estados Unidos, entre outros, ligada à preocupação em se compreender o homem e seu papel no meio. Na década seguinte, estudos na busca pela compreensão da relação entre o meio e a psique humana acabaram por desenvolver a psicologia ambiental como uma disciplina que estuda a relação entre as pessoas e seu entorno com vistas a promover uma harmonia entre ambos, envolvendo o bem-estar humano e a sustentabilidade ambiental. Moser considera que “[...] as dimensões sociais e culturais estão sempre presentes na definição dos ambientes, mediando à percepção, a avaliação e as atitudes do indivíduo frente ao ambiente. Cada pessoa percebe, avalia e tem atitudes individuais em relação ao seu ambiente físico e social." (MOSER, 2001, p. 189-210).

Para Moser (2005), é preciso focalizar o sujeito enquanto usuário do ambiente em estudos que considerem a psicologia ambiental como pressuposto. "A pesquisa nesta seção inclui participação e implicação, diversidade urbana, apego e identidade ao lugar, satisfação residencial e qualidade de vida, vida no subúrbio e modo urbano de vida, crianças e ambiente." (MOSER, 2005, p.133)

Segundo Tuan, nem duas pessoas, nem dois grupos fazem exatamente a mesma avaliação do ambiente, segundo ele "a própria visão científica está ligada à cultura - uma possível perspectiva entre muitas." (TUAN, 1980, p. 06). Isso ocorre porque o ser humano é, na sua relação com o espaço, egocêntrico e tende a perceber o mundo de forma geral a 
partir de seu self, sendo essa uma característica comum quando relacionamos a percepção ambiental. Portanto, para Tuan é particular a forma como cada sujeito age sobre seu espaço e percebe o meio, "o egocentrismo e o etnocentrismo parecem ser traços humanos universais, embora suas intensidades variem grandemente entre s indivíduos e os grupos sociais. Como a consciência fica no indivíduo, é inevitável uma estruturação egocêntrica do mundo." (TUAN, 1980, p. 34).

Nesse sentido, quando tratamos especificamente da percepção ambiental e levamos em consideração o ambiente escolar, para dentro da sala de aula, na qual ocorre a transmissão de conteúdos, a construção da inteligência e a promoção do pensar, a capacidade do sujeito, em que as meninas e meninos realizam escolhas, essa percepção, partindo de uma concepção cognitivista é peculiar. Segundo Vestena, é variada a forma como as crianças julgam e registram o mundo. Para a autora, fatores como a cultura, o sexo, a idade e as experiências com o lugar é que irão elaborar o mapa mental de uma criança para um determinado ambiente. (VESTENA, 2003, p. 11). Portanto, a cultura, a raça e o gênero irão influenciar formas diversas de elaboração mental do lugar e a criança nesse aspecto fica sujeita, além do espaço físico da sala de aula, às experiências vividas nele.

A educação escolar portanto, não pode ser vista como um processo de conceituação consensual, decorrente de práticas educacionais muitas vezes reducionistas, fragmentadas e unilaterais das problemáticas tanto ambiental, quanto cultural, e nem mesmo pode sucumbir a abordagens despolitizadas dessa temática. O entendimento dos sujeitos sobre seu espaço, de que eles devam equacionar valores morais, sociais, culturais e que considerem a multiplicidade de dimensões e de possibilidades na sua percepção ambiental e sua construção do julgamento moral é uma visão nova, não linear de causa e efeito, mas de consideração pela multiplicidade que cerca os temas relacionados aos estudos culturais, cognitivos e sociais. Para Piaget, estudioso do julgamento moral, ...

[…] os espaços vividos, cenários das experiências humanas são sentidos e compreendidos de maneiras distintas pelo ser humano, através dos vínculos cognitivos e afetivos que são estabelecidos por intermédio dos mecanismos perceptivos." (PIAGET, 1975, p. 404-405 apud VESTENA, 2003, p. 9).

Vestena (2003) cita dois planos de distribuição para os mecanismos perceptivos estudados por Piaget, sendo eles: as interações imediatas, resultado da percepção simultânea entre os elementos percebidos e, os efeitos elementares, fruto de análise e exploração. Esse último acaba por desconsiderar a possibilidade de ser inata à percepção ambiental uma vez que considera ser ela resultada numa construção interiorizada.

Para esse texto é considerada a concepção cognitivista e construtivista de Piaget,

[...] essa supera as abordagens anteriores ao considerar que a percepção pode ser analisada quando integrada ao mundo vivido dos indivíduos, tanto no plano cognitivo, perceptivo ou afetivo. Além de compreender que o indivíduo constrói a sua inteligência a partir da interação com o ambiente num processo de equilibrações sucessivas das ações do sujeito. (VESTENA, 2003, p. 09). 
Portanto, cada sujeito perceberá o ambiente de forma diferenciada relacionando os aspectos sociais e culturais próximos à sua experiência de mundo. Ele perceberá o espaço e, experimentando ele, sentirá seus limites e possibilidades, sentindo-se com o passar do tempo confortável para atuar, interferir e criar sobre ele. Haverá um processo de interação e de consciência de seu papel nesse espaço; quando isso ocorrer, o espaço passará a ter significado, pois é fruto da construção do sujeito e passa a ser percebido como lugar.

Porém, é preciso considerar que o ambiente, enquanto espaço, não é estático, a relação entre ele e o sujeito é dinâmico e provoca sua reação, quando isso acontecer surgirão mudanças, conflitos, que levarão esse sujeito a uma adaptação, a uma reorientação de ações e de julgamentos, e essa reflexão é baseada novamente na percepção de regras necessárias para manter o equilíbrio ambiental de forma saudável e autônoma.

Para Rabinovich, "a autonomia pode ser vista como uma apropriação e internalização dos espaços percorridos pelo corpo/sujeito que vão fornecendo uma imagem corporal e de si próprio." (RABINOVICH, 2004, p. 58). Importante portanto, é se antecipar e construir uma percepção ambiental orientada moralmente, ética, internalizada no sujeito de forma que haja a consciência da necessidade em se pensar de forma autônoma o ambiente, em percebê-lo com vistas a garantir o respeito mútuo entre os indivíduos.

Para a escola, espaço de múltiplos saberes, a compreensão da psicologia ambiental e o entendimento do quão múltiplo é o ambiente escolar, pode subsidiar a percepção de que cada indivíduo traz consigo a diversidade inerente a sua construção de realidade e que a promoção de um ambiente capaz de valorizar essa multiplicidade pode propiciar uma convivência respeitosa do coletivo.

Quando identificamos a terra como o ambiente onde se vive, por exemplo, como um ecossistema de possibilidades, percebemos a conexão existente entre o quilombola e o meio e podemos perceber o quanto esse tema tem sido negligenciado no ambiente escolar, isso por inúmeras razões. Uma delas é que para os quilombolas, o meio é exatamente o que os educadores atuais esqueceram: é fonte de afirmação de sua origem, como também é educação, alimento, água, sustento, energia, materiais, amigos recreação ou inspiração espiritual.

Segundo Orr, essa negligência está "na facilidade com que deixamos escapar o imediato e o mundano. Essas coisas mais à mão costumam ser as mais difíceis de ver." (ORR, 2006, p. 117) e complementa "O conceito de lugar é nebuloso para os educadores, porque em grande parte nós consistimos numa população destituída de lugar, para a qual os lugares circundantes não são mais fontes de alimento, água, sustento, energia, materiais, amigos, recreação ou inspiração espiritual." (ORR, 2006, p. 117).

A relação intrínseca existente entre o elemento cultura, o meio onde se vive e o meio da educação é indissociável e complexa para a criança. Quando há conflito entre esses elementos e/ou meios, como casa - escola, o que percebemos com as meninas quilombolas de Paiol de Telha, o dano causado pode refletir na formação de um ser humano não autônomo, não consciente de si no mundo. 
Porém, quando essa complexidade é levada em consideração, um espaço capaz de estimular a convivência do múltiplo surge, seja pela capacitação das pessoas, pela adaptação ao ambiente físico, pelo cuidado em planejar o currículo, entre outros. Quando isso acontece as crianças são motivadas, valorizadas e orientadas à noção de justiça e de regras capazes de construir sua autonomia. São formados acordos mútuos e o julgamento moral da criança pode então se instaurar de forma completa e demonstrar com resultados práticos os valores construídos na interação com o meio e com os adultos que nele convivem.

\section{RELACIONANDO A CONSTRUÇÃO DO JUÍZO MORAL DA CRIANÇA, SEGUNDO A OBRA DE JEAN PIAGET}

A construção da autonomia moral e ética dos sujeitos é possível a todos os indivíduos, segundo Jean Piaget, pois é fruto de sua gênese. Ela depende de muitos fatores como por exemplo um crescimento orientado, um processo de construção operacional equilibrado e adequado à faixa etária deste sujeito e principalmente da interação social com o meio e tudo que nele habita.

Para isso, Piaget tem como sujeito de seus estudos, o sujeito epistêmico, que "refere-se às características mais gerais de estruturação mental. O foco está na investigação das grandes categorias do pensamento: espaço, tempo, causalidade, etc." (SILVA; FREZZA, 2011, p. 191-205). Para Vestena, considerando o sujeito epistêmico, “a moral é resultado inseparável do aspecto lógico e do aspecto social, tanto na maneira como no conteúdo" (VESTENA, 2011, p. 79), pois para Piaget, "toda moral consiste em um sistema de regras." (PIAGET, 1932, p.10).

Segundo Jean Piaget, em seu livro, O juízo moral da criança:

(...) as regras morais, que a criança aprende a respeitar, lhes são transmitidas pela maioria dos adultos, isto é, ela as recebe já elaboradas, e, quase sempre, elaboradas, nunca na medida de suas necessidades e de seu interesse, mas de uma vez só e pela sucessão ininterrupta das gerações adultas anteriores. (PIAGET, 1932, p.11).

Nesse sentido ganham valor dois aspectos fundamentais no que se refere à aprendizagem das regras morais segundo o autor, o respeito que as crianças têm pelo conteúdo das regras e o respeito que têm pelos adultos que repassam as regras, sendo este, $\mathrm{o}$ respeito um modo de sentir que interferirá diretamente na construção de um ser humano capaz de compreender e agir moralmente.

O respeito surge como noção fundamental para o desenvolvimento moral podendo compreender dois tipos específicos: o respeito unilateral e o respeito mútuo. O respeito unilateral implica numa relação de desigualdade, do que tem mais conhecimento para o que não tem, ou do que tem mais experiências de vida, para o que ainda não tem, onde se concebe a coação do superior em relação ao inferior. Ou seja, a criança compreende a relação de respeito, pois essa relação possibilitará um melhor aproveitamento do conhecimento repassado, que consequentemente servirá como arcabouço teórico e prático de 
sua formação. Quando isso ocorre, a criança entende como verdade o que lhe foi repassado, não por ter compreendido totalmente, mas sim por acreditar nessa relação como fonte de afirmação confiável, ou mesmo superior.

Já o respeito mútuo prevê uma relação de cooperação, onde os indivíduos se respeitam reciprocamente. Nessa etapa do desenvolvimento do juízo moral a criança inicia um exercício de justiça. Contrariando o respeito unilateral, exteriorizado, imposto pela regra do certo e errado. Surgem os conflitos, as dúvidas, os questionamentos, os confrontos, principalmente com a autoridade adulta.

Diante disso é necessário saber que existem três fases do desenvolvimento da moral da criança definidas por Piaget: a anomia, a heteronomia e a autonomia: a anomia é a ausência total de regras, o que nos leva a pensar que a moral não é inata. A heteronomia desenvolvida por uma relação de coação é relacionada ao respeito unilateral às regras. A autonomia é viabilizada pelo respeito mútuo, pela cooperação nas relações, construída num processo de interação da criança com o meio, ou seja interiorizada.

Para analisar como se processa o respeito às regras Piaget considerou como uma condição fundamental a necessidade inicial de se pensar como as crianças pensam, ou seja, no nível etário em que se encontram e considerando o lugar onde estão inseridas. Ele buscou nos jogos infantis, que são parte do cotidiano da criança e onde as regras são fundamentais para que a atividade aconteça, um meio de observar e estudar como se dá o julgamento moral da criança. A importância da regra está em, como menciona La Taille, ser ela que "permite dar corpo à moral, situá-la no tempo e no espaço." (LA TAILLE, 2006).

O jogo escolhido foi o de bolinhas de gude por sua popularidade. Além de observar, Piaget também jogava com as crianças e durante a brincadeira conversava com elas sobre as regras do jogo. Essa interação, vivência em comum, demonstrou que as crianças tinham a prática e a consciência da regra e também evidenciou que ambas aconteciam em estágios diferentes. Piaget descobriu que as crianças pequenas, até 3 anos de idade, jogam individualmente, apenas percebem as peças e o espaço do jogo, mas aleatoriamente brincam da forma que quiserem. Testam mais a interação motora, não se preocupando com as regras sociais ou individuais. Já as crianças de 3 a 6 anos de idade aproximadamente, utilizam-se da vivência coagida no seu cotidiano e reproduzem os maiores durante o seu jogar, ao mesmo tempo em que buscam novas alternativas que atendam a seu interesse pessoal, uma característica egocêntrica que também influencia sua capacidade de jogar individualmente, como se mesmo jogando juntos, as regras fossem individuais.

Entre 7 e 10 anos aproximadamente, as crianças percebem que jogar sozinho, para si, causa conflito e começam a se organizar para o jogo, começam a entender a necessidade da regra e criam meios de controle mútuo, o que Piaget chamou de cooperação nascente.

Após os 11 anos de idade aproximadamente, as regras ganham mais importância, pois as crianças percebem sua utilidade e necessidade do ponto de vista da justiça, elas fazem questão de utilizar um tempo de jogo para o detalhamento das regras e para a discussão de novas situações que vão acontecendo durante o jogar. Outra característica 
nessa faixa etária é a aceitação da inovação como parte do jogo. Quando atingem os 11 anos aproximadamente, chega-se a uma consciência da regra como algo que foi elaborado e construído, não algo fruto de coação apenas, mas uma condição igualitária de condições aos indivíduos, onde todos podem intervir. Assim, se percebe a possibilidade de criar e participar da construção das regras de todos e para todos.

Para Piaget, a prática da regra leva a consciência, o autor considera que o conhecimento não é uma cópia da realidade. Conhecer um meio, conhecer um acontecimento não é simplesmente olhar para ele e ter uma cópia ou imagem mental, tal como ele. Conhecer um meio é agir sobre ele. Conhecer é modificar, transformar o meio e entender o processo dessa transformação e como consequência, entender como o meio é construído.

O que Piaget pesquisou está no devir da construção moral nas crianças, sem analises antropológicas ou até mesmo filosóficas. Para ele a epistemologia de seu trabalho é construída racionalmente com base na gênese e onde a cognição é o campo de estudo. Logo, o autor adverte para o fato de os sentimentos morais não serem o foco do estudo aplicado na obra O julgamento moral da criança, mas sim como é construída a evolução dos critérios que chegam ao juízo moral, uma dimensão racional que se baseia originalmente em operações lógicas, em escolhas corretas, como vimos nos estudos das regras do jogo. Assim, Piaget coloca uma relação intrínseca e fundamental entre a moral e inteligência, como também pode parecer que não considera a afetividade na construção da moral, mas para ambas as suposições é preciso uma reflexão.

Piaget estudou a gênese, o processo de maturação, como já foi dito, do julgamento moral nas crianças, mas em outros vários estudos, bem como em cursos que ministrou na Europa, admitiu a possibilidade de que o desenvolvimento da inteligência está relacionado ao desenvolvimento da moral, mas pode não ser determinante. E com relação à afetividade, Piaget considera que o desenvolvimento afetivo, assim como o desenvolvimento intelectual tem relação e ambos são fruto de reorganizações ao longo da evolução da psique.

\section{CONSIDERAÇÕES FINAIS}

Considera-se como esses fatores de vulnerabilidade de gênero e raça estão colocando meninas quilombolas como oprimidas no ambiente escolar e como mola motriz dessa opressão está a diversidade existente nas culturas que habitam a região. No caso, a comunidade quilombola Invernada Paiol de Telha, a relação com seu meio, bem como a disputa pela terra e o valor atribuído ao espaço onde em especial, as meninas quilombolas residem e estudam.

Segundo Pierre Bordieu, a opressão nesse caso pode ser bem representada quando o autor menciona ser essa uma ...

... violência simbólica, violência suave, insensível, invisível as suas próprias vítimas, que se exerce essencialmente pelas vias puramente simbólicas da comunicação e do conhecimento, ou, mais precisamente do desconhecimento, do reconhecimento, ou, em última instância do sentimento. (BORDIEU, 2002, p. 2-3). 
A discussão sobre gênero e espaço é importante e vital nesse caso, pois leva a uma análise de causa e consequência: as meninas quilombolas têm que deixar seu lugar em direção ao lugar de outras etnias para sofrerem o estigma proveniente de uma educação branca e europeia, que pressupõe a dominação masculina e tem na heteronormatização seu princípio histórico.

Nesse aspecto, em Paiol de Telha as meninas quilombolas podem estar passando por um processo de desvalorização e desrespeito do seu lugar e como que procurando um lugar seu acabarão por deixar sua cultura para ceder à dominação existente, sofrendo uma desconstrução cultural. Esse processo colabora para que haja uma negociação identitária, onde as meninas quilombolas aceitam se ver como dominadas, pois entendem ser esse um valor majoritário, atribuído no ambiente escolar.

À escola cabe propiciar ambientes de interação e convivência respeitosos do ser múltiplo, e para isso a psicologia ambiental pode contribuir como ciência que relaciona o indivíduo e o ambiente percebendo como se constituem as relações. Para Moser "a Psicologia Ambiental estuda inter-relações do homem com seu meio ambiente: analisa percepções, atitudes e comportamentos individuais ou comunitários em explicita relação aos contextos físico e social dentro dos quais se vive." (MOSER, 2001, p.191).

Também ao educador é dada a missão de saber conviver e interagir com a multiplicidade de um ambiente, como é o escolar dessas meninas. Humberto Maturana cita, que ao ambiente escolar cabe a instauração de uma cultura de amor ao múltiplo, um sentimento de aceitação ao outro, para ele amar, tem significado de "abrir um espaço de interações recorrentes com o outro, no qual sua presença é legítima, sem exigências." (MATURANA, 2002, p. 23).

As estratégicas educacionais para o múltiplo são as fundamentadas no diálogo, pautadas em um currículo que combata todas as formas de exclusão, onde haja o pressuposto da inclusão como forma de se propiciar um ambiente passível de cuidados e de atenção. O "amor" de Maturana, nesse caso trabalha com a cooperação e a solidariedade como ações morais necessárias entre as pessoas e lida com as diferenças de opiniões negocialmente dialogadas e mediadas, podendo transformar o espaço para que todos vejam a si mesmos e também aos outros, e, para que haja o sentimento de pertencimento.

\section{REFERÊNCIAS}

ABRAMOVAY, M.; CASTRO, M.G. Relações raciais na escola: reprodução de desigualdades em nome da igualdade. Brasília: UNESCO/ INEP, Observatório de Violências nas Escolas, 2006.

ABRAMOVAY, M. Escolas inovadoras: experiências bem-sucedidas em escolas públicas. Brasília: UNESCO, 2003.

ARRUTI, J.M. Quilombos. In. SANSONE, L.; PINHO, O. A. Raça: novas perspectivas antropológicas. 2. ed. Salvador: EDUFBA / Associação Brasileira de Antropologia, 2008. p. 315-350.

BOURDIEU, P. A dominação masculina. Rio de Janeiro: Bertrand Brasil, 2002.

BRASIL. Casa Civil. constituição aa República Federativa do Brasil de 1988. Dispõe sobre Ato das Disposições Constitucionais Transitórias e dá outras providências. Brasília, 1988. 
Instituto Nacional de Estudos e Pesquisas Educacionais Anísio Teixeira. Censo da Educação Básica: 2012. Brasília, 2013.

Secretaria Especial de Políticas de Promoção da Igualdade Racial - SEPPIR. Programa Brasil Quilombola. Brasília, 2004.

Secretaria Especial de Políticas de Promoção da Igualdade Racial - SEPPIR. I Plano Nacional de Desenvolvimento Sustentável dos Povos e Comunidades Tradicionais de Matriz Africana. Brasília, 2013.

Secretaria de Assuntos Estratégicos da Presidência da República. Dossiê mulheres negras: retrato das condições de vida das mulheres negras no Brasil. Brasília: IPEA, 2013.

BRANDÃO, A.P. Saberes e fazeres: modos de ver. Rio de Janeiro: Fundação Roberto Marinho, 2006. v.1.

CIARAMELLO, P.R. (Des) Caminhos Educacionais: da Educação em Comunidade à Universidade. 2014. Dissertação (Mestrado em Educação) - UNICENTRO. Guarapuava, PR.

CRUZ, C.M.; SALLES, J.O. Territorialização negra, conflitos e racismo ambiental no Paraná. In. PARANÁ. Educando para as Relações Étnico-Raciais II. Curitiba, 2008. p. 53-76.

HARTUNG, M.F. O sangue e o espírito dos antepassados: escravidão, herança e expropriação no grupo negro Invernada Paiol de Telha - PR. Florianópolis: NUER/UFSC, 2004.

LA TAILLE, Y. Moral e Ética: dimensões intelectuais e afetivas. Porto Alegre: Artmed, 2006.

LEITE, I.R. Histórias femininas: poder, resistência e educação no Quilombo de Mata Cavalo. 2011. Dissertação (Mestrado em Educação) - Universidade Federal de Mato Grosso. Cuiabá, MT.

MATURANA, H. Emoções e linguagem na educação e na política. Belo Horizonte: Ed. UFMG, 1998.

MOSER, G. Psicologia Ambiental e estudos pessoas-ambiente: que tipo de colaboração multidisciplinar? Revista Psicologia USP, v. 16, n. 1-2, p. 131-140, 2005.

Psicologia Ambiental no novo milênio: Integrando a dinâmica cultural e a dimensão temporal. In: TASSARA, E. Panoramas interdisciplinares para uma Psicologia Ambiental do Urbano. São Paulo: EDUC/FAPESP, 2001. p. 189-210.

MUNANGA, K. Origem e histórico do quilombo na África. Revista USP, v. 28, p. 56-63, dez./ fev. 1995/1996.

O’DWYER, E. Os quilombos e a prática profissional dos antropólogos. In. Quilombos: identidade étnica e territorialidade. Rio de Janeiro: FGV, 2002. p. 13-42.

ORR, D.W. Lugar e pedagogia. In: CAPRA, F. Alfabetização ecológica: a educação das crianças para um mundo sustentável. São Paulo: Cultrix, 2006. p. 114-124.

PIAGET, J. O Julgamento Moral da Criança. São Paulo: Mestre Jou, 1932.

Piaget. São Paulo: Abril, 1975. (Coleção os Pensadores).

RABINOVICH, E.P. As transformações na vida das crianças e na cidade - um estudo de caso. In: GUNTHER, H.; PINHEIRO, J.Q; GUZZO, R.S.L. Psicologia ambiental: entendendo as relações do homem com seu ambiente. Campinas: Alínea, 2004. p.54-100.

RATTS, A. A Face Quilombola do Brasil. In: SILVÈRIO, V.R; MATTIOLI, E.A.K; MADEIRA, T. L. Relações étnico-raciais: um percurso para educadores. São Carlos: Ed. UFSCAR, 2013. v.2, p.129-150.

SCOTT, J. Gênero: uma categoria útil de análise histórica. Revista Educação e Realidade, Porto Alegre, n. 20, p. 71-99, 1995.

SILVA, J.A.; FREZZA, J.S. Aspectos metodológicos e constitutivos do pensamento do adulto. Educar em Revista, Curitiba, n. 39, p. 191-205, jan./abr. 2011.

SIQUEIRA, M.L. Os Quilombos e a Educação. In: BRASIL. Ministério da Educação. Valores afro-brasileiros na Educação. Brasília, 2005. (Boletim 22, Salto para o Futuro/TV Escola). p. 37-42.

TUAN, Yi-Fu; Espaço e lugar: a perspectiva da experiência. São Paulo: Difel, 1983.

Topofilia: um estudo da percepção, atitudes e valores do meio ambiente. São Paulo: Difel, 1980. 
VESTENA, C.L.B. Sensibilização Ambiental: um diagnóstico na Bacia Hidrográfica do Rio Belém, Curitiba - PR, a partir da percepção de alunos do ensino fundamental. 2003. Dissertação (Mestrado em Geografia) - Universidade Federal do Paraná. Curitiba, PR.

Piaget e a questão ambiental: sujeito epistêmico, diagnóstico e considerações educacionais. São Paulo: Cultura Acadêmica, 2011.

Recebido para Avaliação em 18-05-2014 Aceito para publicação em 31-07-2014 